\title{
Behind Enemy Lines: Immunomodulatory Armamentarium of the Schistosome Parasite
}

\author{
Jose Ma. M. Angeles*, Van Jerwin P. Mercado and Pilarita T. Rivera \\ Department of Parasitology, College of Public Health, University of the Philippines Manila, Manila, Philippines
}

The deeply rooted, intricate relationship between the Schistosoma parasite and the human host has enabled the parasite to successfully survive within the host and surreptitiously evade the host's immune attacks. The parasite has developed a variety of strategies in its immunomodulatory armamentarium to promote infection without getting harmed or killed in the battlefield of immune responses. These include the production of immunomodulatory molecules, alteration of membranes, and the promotion of granuloma formation. Schistosomiasis thus serves as a paradigm for understanding the Th2 immune responses seen in various helminthiases. This review therefore aims to summarize the immunomodulatory mechanisms of the schistosome parasites to survive inside the host. Understanding these immunomodulatory strategies not only provides

OPEN ACCESS

Edited by:

Yasuyuki Goto,

The University of Tokyo, Japan

Reviewed by:

Debora Decote-Ricardo,

Universidade Federal Rural Do Rio de

Janeiro, Brazil

Patrick Skelly,

Tufts University, United States

${ }^{*}$ Correspondence:

Jose Ma. M. Angeles jmangeles3@up.edu.ph

Specialty section:

This article was submitted to Microbial Immunology,

a section of the journal

Frontiers in Immunology

Received: 15 December 2019

Accepted: 28 April 2020

Published: 09 June 2020

Citation:

Angeles JMM, Mercado VJP and Rivera PT (2020) Behind Enemy Lines: Immunomodulatory Armamentarium

of the Schistosome Parasite.

Front. Immunol. 11:1018.

doi: 10.3389/fimmu.2020.01018 information on parasite-host interactions, but also forms the basis in the development of novel drugs and vaccines against the schistosome infection, as well as various types of autoimmune and inflammatory conditions.

Keywords: schistosomiasis, immunomodulation, innate immunity, parasite, Th2 immune response, cytokines

\section{INTRODUCTION}

Immunomodulation is a tactic employed by parasites to successfully invade their human hosts. As an adaptive survival skill, helminths employ a great diversity of immunomodulatory strategies for evading immune detection, suppressing cellular immunity, and eluding host immune attacks $(1,2)$. These promote their longevity inside the host to further continue their life cycle and facilitate transmission.

Unlike the rapidly multiplying protozoan parasites, some of which use antigenic variation as an effective evasion strategy in escaping immune recognition (3), the chronicity of helminthic infections has led helminths to act against the host immune responses by downmodulating the latter's intensity and effectiveness. Schistosoma parasites have been shown to induce the Th2 response that is shown to be more favorable to important biological processes inside the host such as migration and egg excretion (4). During its intra-mammalian life cycle, Schistosoma needs to conquer a war zone consisting of the host's innate and adaptive immune responses. The life stages of the parasite that will have to contend with the host's immune system are the penetrating cercariae, the migrating schistosomula, the adult worms, and the eggs produced by the adults in copula.

During schistosome infection in the mammalian host, cytokines play major roles in the regulation of immune and inflammatory responses against invading parasites. These effector molecules, particularly those produced by the immune cells, not only mediate both physiological and pathological consequences at the onset of immune response, but also control the degree and duration of such a response. The schistosome parasites are therefore equipped with 
immunomodulatory armamentarium acting as counter-defenses to protect themselves from the destruction brought about by host immune attacks. This review aims to provide a summary of these immunomodulatory strategies that might be crucial for the survival of the schistosomes within their definitive host.

\section{INFILTRATING HOST TERRITORY}

The skin is the largest organ of the body and consists of a complex network of different cell types that maintain several vital processes including immune responses for disease prevention. The schistosome cercariae begin their invasion by infiltrating the skin- the host's primary defense. During invasion, the parasite needs to ensure its survival by orchestrating immune regulation within the skin. The percutaneous entry of the schistosomula elicits an inflammatory response characterized by infiltration of polymorphonuclear cells (PMNs) and mononuclear cells $(5,6)$. Localized production of pro-inflammatory cytokines including interleukin (IL)-1b, IL-6, IL-12, and tumor necrosis factor (TNF)$\alpha(7,8)$ is supposed to promote this pro-inflammatory Th1 response. However, invasion by the schistosome paradoxically leads to predominantly Th2 immunity. This skewing of the immune response arises from the production of certain immunoregulatory mediators. IL-10, produced by keratinocytes, macrophages, dendritic cells (DCs) and B1 lymphocytes, is one of these key immunomodulatory cytokines elaborated in the skin in response to the cercarial invasion (9). In addition, a major molecule from the secreted protein of the cercaria known as Sm16 has been shown to modulate innate immunity by preventing macrophage classical activation and delaying antigen processing (10). Sm16 is also capable of blocking the activation of IL-1 receptor-associated kinase 1 (IRAK-1) gene, which is important in the production of nuclear factor kappa-light-chain enhancer of activated B cells (NF- $\kappa \mathrm{B})(11)$. NF- $\kappa \mathrm{B}$ is known to be a key player in the regulation of immune responses to infection (12).

Excretory-secretory (ES) products from the cercaria likewise stimulate inhibitory molecules like prostaglandins. Studies have shown that schistosomula can induce prostaglandin E2 (PGE2) production in the human keratinocytes (13). This overexpression of PGE2 in the skin plays an important role in the production of IL-10 through a cyclooxygenase 2-dependent pathway (14). In addition, PGE2 is also a potent vasodilator (15) aiding the passage of the schistosome into the circulation. In fact, in a murine model for Schistosoma mansoni, PGE2 has been documented to be the main immunoregulatory molecule in the skin (13).

Langerhans cells (LCs) are considered the first-line fighters in the skin considering their location in the outer layers as compared with other types of DCs (16). LCs are known to induce immunological tolerance $(17,18)$, and their suppressive effects arise from IL-10 production and CD4+ regulatory $\mathrm{T}$ cells induction (19). When the skin is invaded by pathogens such as schistosomes, keratinocytes and LCs produce pro-inflammatory cytokines such as TNF- $\alpha$ and IL-1b stimulating the actindependent migration of the LCs (20). Another prostaglandin, now produced as a component of the schistosomula's ES proteins, prostaglandin D2 (PGD2) together with PGE2 leads to increased production of IL10 (21). The anti-inflammatory IL-10 downregulates the production of both IL- $1 b$ and TNF- $\alpha$, thus inhibiting the migration of epidermal LCs to the site of invasion (21). Overall, this disruption in the movement of antigen presenting cells (APCs) from the site of exposure to the draining lymphoid tissue is a vital immunomodulatory strategy adopted by the Schistosoma parasites (21).

Mast cells (MCs) are another key player in the immune response against parasitic infections. MCs are abundant near cutaneous and mucosal body surfaces where early immune surveillance occurs. The schistosome parasite has been shown to release ES proteins that can induce mast cell degranulation (22). One of these molecules is likely to be the schistosome homolog of the human translationally controlled tumor protein (TCTP) that has been shown to degranulate both basophils and mast cells (23). Binding of histamine from activated mast cells to $\mathrm{H} 2$ histamine receptors induces IL-10 production in maturing DCs $(24,25)$ and inhibits the production of Th1 promoting cytokine IL-12, which in turn is a powerful inducer of interferon- $\gamma$ (IFN- $\gamma$ ) (26). This results in matured DCs polarizing naive CD $4+\mathrm{T}$ cells toward the Th2 phenotype (24).

Parasites can also regulate the host's immune response by inducing apoptosis of host cells (27). A $23 \mathrm{kDa}$ protein called S. mansoni apoptosis factor (SMAF) has been characterized as a component of the cercarial ES products that can trigger apoptosis in the CD4+ lymphocyte population via Fas-FasL interaction. The same study suggests that the CD4+ cell apoptosis modulates the host's immune response and allows the schistosome parasite to evade immune surveillance (28).

Studies have also shown that ES products from the schistosomula stimulate APCs toward Th2 immune responses. ES-activated DCs trigger CD4+ cells to produce regulatory cytokines IL-4, IL-5, and IL-10-, all indicative of a Th2 response (29). Furthermore, these DCs also lose the ability to produce Th1-promoting cytokines including IL-12, IL-23, and IL-27 (30). It thus appears that immunomodulatory molecules in the ES products could modify the APCs to promote Th2 responses over the Th1 phenotype (31).

\section{CAMOUFLAGING OF THE MIGRATING SCHISTOSOMULA}

Skin-stage schistosomules are susceptible to both humoral and cellular immune responses. However, the significant morphological and biochemical changes occurring in the developing schistosomula render them resistant to the host immunological defenses (32), as seen in the lung schistosomulum $(33,34)$. These changes include shedding of the cercarial membrane and formation of the heptalaminate surface membrane (35). This unique outer-surface tegumental membrane might be an adaptation to resist host immune effectors such as complement activation and antibody-dependent cell-mediated cytotoxicity (ADCC) $(36,37)$. Different immune evasion strategies have been proposed to explain the inefficient 
host immune response against the exposed schistosome tegument (37). These include rapid tegument turnover, masking with acquired host antigens, and poor immunogenicity of exposed antigens (38).

Danger-associated molecular patterns (DAMPs) are tissuederived distress signals released during stress or injury. One such DAMP is extracellular ATP involved in purinergic signaling (39). Extracellular ATP has been shown to induce the degranulation of neutrophils and the production of proinflammatory cytokines in macrophages and monocytes (40). Ecto-enzymes, such as alkaline phosphatase, phosphodiesterase, and ATP diphosphohydrolase, have been found to be expressed in the tegument of schistosomula (41-43). These ecto-enzymes might catalyze the conversion of ATP to adenosine and effectively degrade DAMPs released by host cells in response to intravascular schistosome migration, interfere with purinergic signaling, thus preventing pro-inflammatory responses, and subsequently lowering host immunity against the parasite (44).

Aside from their role against the pro-inflammatory ATP, these ecto-enzymes also inhibit blood coagulation in the tissue vicinity (45). Platelets themselves have been shown to damage the schisosome parasite (46). The catabolism of ATP and ADP through the ecto-enzymes characterized in S. mansoni, including the tegumental ecto-apyrase ATP diphosphohydrolase (SmATPDase-1) (47), alkaline phosphatase (SmAP) (48), and phosphodiesterase (SmNPP5) (49), may lead to the inhibition of platelet aggregation and thrombus formation around the worm. Moreover, activated platelets and immune cells release inorganic polyphosphates (polyPs) $(50,51)$. polyPs are essential for the activation of factor XII, which triggers the kallikrein-mediated kininogen pathway, thus producing high levels of bradykinin, increasing vascular permeability, and promoting inflammatory responses (52). SmAP has been shown to hydrolyze polyPs in vitro thereby possibly preventing their action against the parasite (48). This SmAP-mediated cleavage of polyPs may therefore contribute to the survival of the intravascular stages of the schistosome parasite, including the schistosomula and the adult pairs within their hostile habitat (48).

Lung schistosomula need to resist immune damage as they have been shown to activate complement (53) and bind antibodies on their surface membrane (54). Therefore, the structural and biochemical modifications of the schistosomulum's surface membrane tend to produce immunological camouflage that either prevent antibody binding or effectively reduce antigen expression (32). Furthermore, caveolin-like molecules and membrane fractions characteristic of detergent-insoluble glycosphingolipid-enriched membrane domains (DIGs) or detergent-resistant membranes (DRMs) have been observed on the surface membrane of the schistosome (55), thus indicating the presence of lipid-rafts (56) that might serve as an additional protection for the parasite. Lipid rafts are presumed to enable signal transduction by selectively concentrating intracellular signaling molecules in which protein kinases, scaffolding molecules, and substrates are in close proximity (57). In schistosomes, the lipid rafts have been shown to possess specialized signaling domains such as protein kinase $\mathrm{C}$ (PKC) and extracellular signal-regulated kinase (ERK) (58).
PKC and ERK are important mediators known to regulate diverse processes in eukaryotes such as growth, development and differentiation, cell cycle, motility, apoptosis, and survival $(59,60)$.

Moreover, genes associated with immune evasion and stress responses, such as the potent anti-inflammatory $\mathrm{Sm-16}$ and paramyosin, are over-expressed in lung schistosomula (61). Sm16 might play a crucial role in the interaction of the parasite with immunoreactive lung microvasculature endothelial cells during the passage of the schistosomulum through the lung (62). On the other hand, paramyosin, found on the tegumental surface of the schistosomula, aids in immune evasion through its receptor that is capable of adsorbing antibodies onto the parasite surface at the latter's Fc regions $(62,63)$.

Nitric oxide (NO) plays a very important role both in the mammalian hosts and in helminths with respiratory pathology (64). It is a key messenger in the pathogenesis of inflammation by acting as a signaling molecule during $\mathrm{T}$ cell-mediated immunity (65). IFN- $\gamma$ up-regulates inducible nitric oxide synthase (iNOS) leading to the production of NO (66). This cytokine is produced by the immune effector $\mathrm{CD} 4+\mathrm{T}$ cells as an immune response against the schistosomula in the lungs (66). In an experimental study comparing the susceptibilities of different stages of larvae to killing by NO, lung schistosomula obtained 1 week after infection were not killed in vitro by $\mathrm{NO}$ generated either from a chemical NO donor or from activated cells (67). At this period, the schistosomula has been shown to undergo anaerobic metabolism (68), thus negating the aerobic metabolism-dependent effects of NO against the parasite (67). During transformation of cercaria into schistosomulum, the parasite rapidly shifts from carbon dioxide production via the Krebs cycle to lactate production using glycolysis (69), and from consumption of stored glycogen to dependence on host glucose as fuel (70). Furthermore, schistosomula have higher levels of mRNAs associated with anaerobic glucose metabolism (70) and lower expression of respiratory enzymes (71). As the schistosomes develop into adults, however, they regain a significant capacity to produce energy via aerobic metabolism (70).

Once the schistosomulum becomes successful in evading the host's immune response, it goes into the portal veins and matures into an adult over a period of 1-3 weeks. The male and female adult schistosomes pair up, adhere to the veins, bring forth 300-3,000 eggs, and escape host immunity for many years.

\section{SURVIVAL OF THE ADULT PAIRS IN THE VASCULAR SYSTEM}

The major task of the adult schistosomes is to produce eggs while surviving within the vascular system of the host. The circulatory system is home to various immune defenses including immune cells, phagocytes, complement proteins, and antibodies. However, the adult schistosomes are capable of avoiding the immune recognition system by coating their outer tegument with antigens from the hosts. Several studies have shown that the adult Schistosoma parasites were covered with immunoglobulins, 
$\beta 2$ microglobulin, complement components, and other host antigens (72-75).

The complement system is an essential component of innate host immunity, and therefore schistosomes should protect themselves from complement-dependent cytotoxicity. To avoid complement-mediated auto-hemolysis, host erythrocytes are provided with a $70-\mathrm{kDa}$ glycosylphosphatidylinositol (GPI)anchored protein known as decay accelerating factor (DAF), which inhibits $\mathrm{C} 3$ convertases in both the classical and alternative pathways of the complement system (76). An in vitro experiment showed that adult schistosomes were capable of abstracting DAF or CD55 from host erythrocytes, which then serves as a valuable defense against the action of the complement system (77). The adult schistosomes are also provided with inhibitors of human complement activation on their tegument such as the trispanning orphan receptor of S. haematobium (Sh-TOR), a receptor that can bind specifically to human complement C2 (78). Finally, paramyosin is a known inhibitor of the complement membrane attack complex. It has been discovered that earlier known complement inhibitor SCIP-1 (34) is just a surfaceexposed form of paramyosin (79). Paramyosin might therefore have some significance in the immunomodulation by inhibiting the activation of the terminal pathway of the complement system (79).

\section{SKEWING OF IMMUNE RESPONSE}

Following schistosomule migration, a Th1 immune response is elicited as characterized by a marked increase in IL-1 and IFN$\gamma$ induced by the worm antigens (80). The Th1 response persists for approximately 5 weeks. However, as the parasites mature, the immune response is skewed into the Th2 type (30). Experimental single-sex infections in mice models have shown that both male and female worms individually induce IL- 4 production by CD $4^{+}$ $\mathrm{T}$ cells and promote a Th2 response even before eggs are laid (31).

Toll-like receptors (TLRs) are a family of pattern recognition receptors expressed in cells of the innate immune system such as macrophages and DCs (81). Activation of TLRs induces Th1 immune response with a predominant production of IFN- $\gamma$ by the CD4+T cells (82), in addition to Th1 promoting cytokines IL-12, IL23, and IL27 secreted by APCs (83). In S. mansoni, the TLR2 and TLR4 of DCs have been shown to recognize the schistosome specific phosphatidyl serine-containing lipid antigen lysophosphatidylserine (lyso-PS) (84), and lacto-N-fucopentose III (LNFPIII), respectively, in the worm's ES (85). These TLRmediated signaling reduces the ability of the DCs to produce IL12 and promotes a polarization toward a Th2 immune response instead of the Th1 type. Ligation of LNFPIII and the TLR4 in DCs by Schistosoma induces phosphorylation of mitogenactivated MAP kinase (MAPK) ERK (85). On the other hand, the schistosomal lyso-PS has been shown to induce activation of DCs promoting Th2 and regulatory $\mathrm{T}$ cell development via a TLR2-dependent mechanism (84). TLR2 ligation stabilizes the MAPK ERK, and stimulates the transcription factor cFos, thereby suppressing IL-12 production, and promoting polarization toward Th2 immune responses (86).
At 5-6 weeks post-infection, the adult female schistosomes start to release eggs after pairing with the male worm. The schistosome eggs evoke a host immunity that is more robust compared with the ineffective response mounted against invading cercariae and adult worms (87). Eggs of S. haematobium have been shown to elicit an immediate, initial response within $24 \mathrm{~h}$ upon release, marked by the induction of pro-inflammatory mediators such as TNF- $\alpha$, on one end, and that of antiinflammatory cytokines that include CCL11 (88). Schistosome eggs, viable or dead, are remarkably capable of inducing Th2 responses (89). This Th2 phenotype is characterized by the proliferation of Th2 cells, eosinophils, and basophils; elevated production of immunoregulatory cytokines IL-4, IL-5, and IL13; and polarization of antibodies toward the $\operatorname{IgG} 1$ and $\operatorname{IgE}$ isotypes, and of macrophages toward M2 phenotype (90, 91). The ES proteins, such as the dimeric glycoprotein alpha-1 $(\alpha 1)$ or IL-4 inducing principle of schistosome eggs (IPSE), and the hepatotoxic egg glycoprotein omega-1 ( $\omega 1)$, thus play important roles in the immunomodulation of the CD4+ effector responses (92-95). Specifically, the ribonuclease activity of $\omega 1$ protein in the ES of $S$. mansoni eggs is found to be essential in inducing Th2-type response in DCs (94).

\section{JOURNEY OF THE SCHISTOSOME EGGS}

Schistosome eggs exit the host either by traversing the intestinal wall into the intestinal lumen via mesenteric vessels for $S$. mansoni and $S$. japonicum, or through migration into the vesical lumen of the bladder for S. haematobium (96). This egg expulsion however is mostly host-dependent as the schistosome eggs lack any motility mechanisms (97). As egg passage into the intestine is not guaranteed, about half of all the deposited eggs accidentally go to the liver (98). In order to continue transmission, the schistosome parasites employ strategies to ensure successful egg transit into the environment (98-101). Extravasation in the blood vessels is promoted by angiogenesis, endothelial activation, and fibrinolytic activity induced by schistosome eggs. The eggshell contains the enzymes enolase and glyceraldehyde-3-Pdehydrogenase (102) that act as surface binding receptors to plasminogen $(103,104)$. It was proposed that once it has reached the intestine, the schistosome induces granuloma formation to promote egg excretion, while at the same time preventing severe immunopathology that may otherwise affect egg release (105). It was previously noted that schistosome egg excretion is an exquisite, immune-dependent process (106).

The polarization of Th cells determines the macrophage phenotype and granuloma formation. M2 macrophage phenotype or alternatively activated macrophages are needed in effective granuloma formation and confer protection against excessive damage of the eggs during their movement across the intestinal tissue (105). M2 phenotype is promoted by IL4/IL-13 release from Th2 cells in S. mansoni infection (106). This has been proven by the impaired granuloma formation during schistosome infection in T cell derived IL-4 and IL-13 deficient mice inhibiting the egg release into the intestinal lumen $(107,108)$. These mechanisms may suggest that Th2 immune 
responses collaborate with egg-derived proteases in promoting egg release from intestinal tissues.

\section{IMMUNOMODULATION IN THE GRANULOMA FORMATION}

Unlike in intestinal granulomata, where schistosome eggs have the ability to exit into the gut lumen, the eggs in the hepatic granuloma remain trapped, with the granuloma becoming fibrotic over time. Secretions from the trapped eggs are known to stimulate the CD4+ T cells initially to release Th1-type cytokines IL-2 and IFN- $\gamma$ facilitating delayed-type hypersensitivity reaction and early granuloma formation (90). This immune response gradually shifts to the Th2 phenotype with the production of IL-4, IL-5, IL-10, and IL-13 (90, 109-113). It has been shown that hepatosplenic schistosomiasis, a severe form of the disease, is associated with increased levels of Th1 cytokines TNF- $\alpha$ and IFN- $\gamma$, and decreased levels of Th2 cytokine IL-5 in a study done using peripheral blood mononuclear cells from patients (114). This proves that the outcome of the disease is dependent on the type of immune response elicited by the parasite within the host. In addition, S. mansoni eggs were shown to secrete chemokine binding protein (smCKBP) that is believed to block certain chemokines from inducing granuloma formation while preferentially altering the cellular features of the granuloma (115). Both in vitro and in vivo experiments have demonstrated that smCKBP tends to prevent the interaction of chemokines such as CXCL8 with specific cellular receptors, as well as the activation and migration of immune cells such as neutrophils (115).

Granuloma formed during prolonged Th1 response and a dampened Th2 response have been shown to display decreased size and fibrosis owing to downregulation of inflammation and of collagen deposition (116). This phenomenon might be attributed to the dominance of neutrophils infiltrating the lesion during the initiation of granuloma formation (117). Neutrophils are recruited by egg-specific proteins (118) to the core of the granuloma leading to a neutrophil-mediated inflammatory response that causes tissue damage (117). In addition, intact live eggs and soluble egg antigen (SEA) can trigger the release of neutrophil extracellular traps (NETs) within the core of the granuloma, potentially limiting the pathogenic effects of parasite eggs (119). NETs are web-like structures consisting of de-condensed chromatin and histones produced by activated neutrophils and are thought to be involved in pathogen trapping, including parasites such as Plasmodium falciparum (120) and Strongyloides stercoralis (121). A previous study has shown that eggs trapped within the mesh of NETs remain viable and were not killed, as opposed to the effect of NETs as seen in other pathogens (119). This might suggest that NETs only serve to immobilize or restrict the movement of the schistosome eggs, without adversely affecting their viability.

At a later stage of the disease, neutrophils secrete granule proteins that can degrade collagen, the major component of fibrotic granulomas, thus limiting the size of the granulomas. S. japonicum granuloma has neutrophils that accumulate within the core as early as 8 days post-deposition $(122,123)$, and at the periphery as granuloma matures (124). This implies that neutrophils have different roles in the granuloma formation depending on the time of their recruitment and their location within the lesion.

Although CD4+ T cells generally dictate the granulomatous response to the eggs, other immune cells like CD8+ T cells, B cells, M2 macrophages and eosinophils are also as important in the regulation of granuloma formation (125-128). Eosinophil infiltration in the granuloma is mediated by IL-5 and IL-13 $(112,127,129,130)$. This Th2-driven eosinophil infiltration in the granuloma stands in contrast with the early Thl granuloma, which is dominated by neutrophils. Aside from the destructive actions directed against miracidia within trapped eggs upon their degranulation (131), eosinophils are also responsible for the polarization of the immune response to Th2 type by producing IL-4 and IL-5 (132). Granuloma in S. mansoni has been noted to have more eosinophils than neutrophils, which is in contrast to the neutrophil dominated granuloma seen in S. japonicum (133). The number of eosinophils in S. mansoni infection were $60.60 \pm 0.47 \%$, and $44.30 \pm 0.23 \%$ of all the granuloma cells in the acute and chronic experimental infections, respectively, using murine models for both hepatic and intestinal infection (134). In an earlier experiment done using murine models for lung granuloma, results showed about $70 \%$ of the cellular population in S. mansoni granuloma are eosinophils at 16 days post-deposition (125).

CD4+ T cells are the primary source of IL-13 (135), the dominant Th2 cytokine responsible for the development of liver fibrosis (136). Together with IL-4, IL-13 induces macrophage expression of arginase, which then cleaves L-arginine to form L-ornithine (136). Ornithine aminotransferase then converts Lornithine to proline, which is important in collagen production and fibrosis development (137). IL-13 also triggers the transdifferentiation of hepatic stellate cells (HSCs), one of the main sources of hepatic collagen, and plays an important role in schistosome-induced fibrogenesis (138).

The granuloma both functions as a major pathology in schistosomiasis disease and as a protective barrier between the egg and the liver tissues. Although the Th1-dominated immune response gives rise to granulomas with smaller sizes and less fibrosis, the switch to the Th2 phenotype confers some protective effects to the host (139). The granuloma functions to sequester egg secretions that can otherwise cause damage to liver tissue (139).

\section{THE DUAL ROLE OF TGF- $\beta$}

Th17 serves as a unique CD4+ T cell subset and is characterized by IL-17 production as an adaptive host mechanism in cases where both Th1 and Th2 immune responses are inappropriate for protection against the pathogen (140). IL-17 is a proinflammatory cytokine often seen in the pathogenesis of autoimmune diseases. In S. japonicum, SEAs are believed to induce a Th17 response (141) linking it to severe hepatic inflammation in schistosomiasis $(142,143)$. The association 


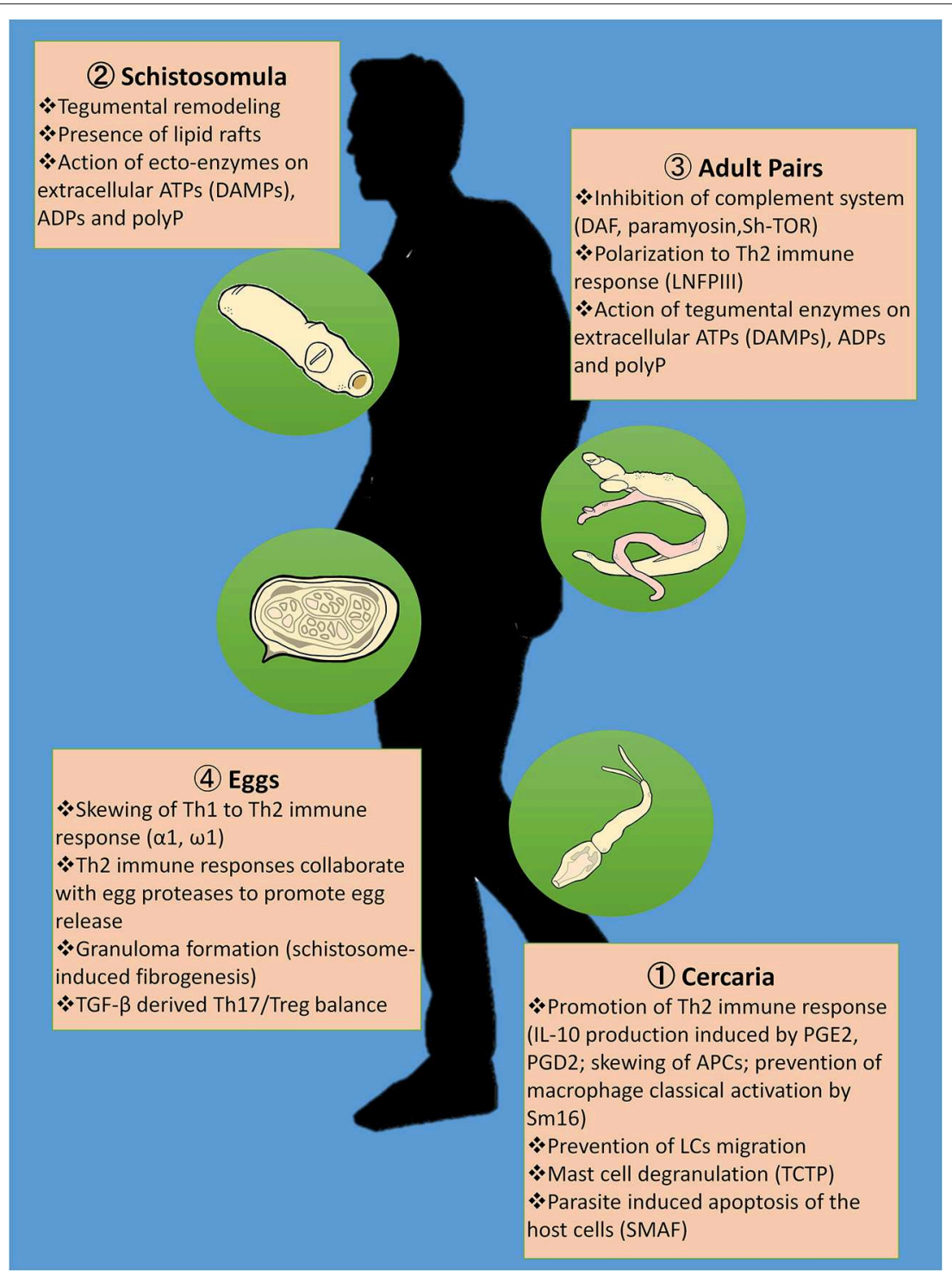

FIGURE 1 | Summary of proposed immunomodulatory strategies of the schistosome in evading the host immune responses. Skewing of Th1 to Th2 immune response is very much evident during cercarial penetration (1) through IL-10 production induced by prostaglandin E2 (PGE2) and prostaglandin D2 (PGD2), prevention of macrophage classical activation by Sm16 and disorientation of the antigen presenting cells (APCs); lodging of the adult schistosome pairs in the veins (3) through the interactions between lacto-N-fucopentose III (LNFPIII) and toll like receptors (TLRs); and egg deposition in the intestinal and liver tissues (4) through the immunomodulatory effects of the egg's excretory-secretory proteins (ES) to CD4+ effector responses including $\alpha 1$ and $\omega 1$. In addition, the cercariae 1 are able to evade innate immunity in the skin by preventing migration of Langerhans cells (LCs), mast cell degranulation promoted by the translationally-controlled tumor protein (TCTP) homolog in schistosomes, and Schistosoma mansoni apoptosis-inducing factor (SMAF)-mediated host cell death. Schistosomula's (2) tegumental remodeling and the presence of lipid rafts covering the parasite render them undetectable to immune responses during migration. Once the adult schistosomes (3) settle in the mesenteric veins, they become capable of evading the host complement system through the abstraction of erythrocytes' decay-accelerating factor (DAF) as seen in in vitro studies, the binding of human complement C8 and C9 to the schistosome's paramyosin, and the attachment of C2 to the trispanning orphan receptor of Schistosoma haematobium (Sh-TOR). Ecto-enzymes on the tegument of intravascular stages including the (2) schistosomula and (3) adults cleave extracellular ATPs that otherwise serve as damage-associated molecular patterns (DAMPs) as well as ADPs and inorganic polyphosphates (polyPs), thereby interfering with host pro-inflammatory and prothrombotic purinergic signaling. Eggs from the schistosomes in copula (4) express proteases that may aid in egg egress in addition to Th2 immune responses. Granuloma formation with schistosome-induced fibrogenesis tends to limit tissue destruction brought about by egg deposition. However, disease severity is largely determined by Th17/Treg balance mediated by transforming growth factor- $\beta$ (TGF- $\beta$ ).

between Th17 and the severity of the disease is also seen in S. mansoni infection as an exacerbation of granuloma in mice models is primarily directed by a Th17 response $(144,145)$. The role of IL-17 in granuloma formation is further proven by a decrease in the size of granulomata when anti-IL-17 neutralizing antibodies were given to infected mice (142).

Th17 differentiation is induced in mice exposed to transforming growth factor- $\beta$ (TGF- $\beta$ ) and IL-6 (146-148). 
As TGF- $\beta$ is also known to induce differentiation of CD4+ $\mathrm{T}$ cells into forkhead box protein 3 (FoxP3)-expressing regulatory T cells (Tregs) (149), the pivotal role of TGF- $\beta$ in the progress of the disease makes it one of the most important cytokines that determines disease outcome. Th17 cells promote inflammation through the production of IL-17, IL-22, and IL-23, and neutrophil recruitment (150), whereas Tregs produce the anti-inflammatory cytokines IL-10 and TGF- $\beta$ (151). Surprisingly, Tregs can be transformed into Th17 cells in the presence of IL-6 (152). Interestingly, Th17 cells appear to be resistant to Tregs' suppressive effects $(153,154)$. Thus, the delicate balance maintained between anti-inflammatory Tregs and pro-inflammatory Th17 cells is a prime determinant in disease severity. The imbalance of Th17/Treg has been shown to be closely associated with immunopathological damage and egg granuloma formation in mouse models infected with $S$. japonicum (155).

Currently, not much is known about how the balance between the Th17/Treg immune responses modulates disease progression in schistosomiasis. It is therefore worthwhile to elucidate which mechanisms promote Treg proliferation during the chronic phase of schistosome infection when Th2 immune responses start to wane and lead to immune hypo-responsiveness.

\section{CONCLUSION AND FUTURE DIRECTIONS}

Schistosomiasis is a neglected tropical disease whose transmission has been reported in 78 countries. This parasitic disease has been a public health problem as early as 5,000 years ago upon being discovered in Egyptian mummies (156). This long relationship between humans and the schistosome parasites has enabled the latter to adopt various strategies to successfully survive inside the host. Figure 1 shows the summary of proposed immunomodulatory armamentarium that schistosome parasites utilize in order to evade the host's immune responses, and thus facilitate infection. Understanding the mechanisms behind these immunomodulatory strategies will not only shed light on host-parasite interactions but also be useful in the development of novel treatments against the schistosome parasite.

Parasitic helminths like Schistosoma spp. are said to be capable of limiting intraspecific competition inside the host via concomitant immunity (157). Concomitant immunity is the production of effective anti-larval immunity that does not harm the existing adults. The adult worms might be "vaccinating" the host with cross-reactive antigens creating a barrier against new infection. This has been proven with an experimental study involving monkeys infected with adult schistosomes via surgical transplants (158). The monkeys showed resistance to cercarial challenge even though they were not exposed to any larval schistosome stages. However, another study has looked into potential mechanisms causing elimination of lung schistosomula in mice previously vaccinated with irradiated cercariae (159). Results show that the deflection of the parasites in the alveoli during migration was the reason many failed to mature in both vaccinated and unvaccinated mice, as no inflammatory reactions against the parasites have been found in the skin and lungs of the vaccinated mice (159). A better understanding of the role of immunomodulation in the early stage of schistosome infection might be the key in the production of a "true" effective anti-larval immunity against Schistosoma.

The 2-fold ability of the helminth worms to downregulate pro-inflammatory cytokines and skew Th1 to Th2 type immune responses has suggested their possible use in treating other illnesses such as autoimmune and inflammatory diseases, thus supporting the hygiene hypothesis (160). This hypothesis states that persons who never contract infections run the risk of developing autoimmune diseases, as infections facilitate the development and regulation of the immune system (161). Therefore, immunomodulatory molecules elaborated in response to the schistosome parasite can serve as potential tools to control overt immune responses.

Experimental studies have demonstrated the immunomodulatory effects of schistosome infection on arthritis (162-164), type 1 diabetes (165-168), Graves' disease (169), and airway allergies $(170,171)$. The therapeutic potentials of immunomodulatory molecules such as smCKBP might be used as selective manipulators of the immune system to prevent immune-mediated diseases (115). The schistosome-derived carbohydrate LNFPIII might be useful in treating type 2 diabetes as its administration in mice has improved glucose tolerance and insulin sensitivity (172), and in psoriasis as it induces Th2 immune response, and subsequent amelioration of skin lesions (173). Purified cystatin from S. japonicum has been shown to reduce inflammatory parameters and decrease the severity of trinitrobenzene sulfonic acid (TNBS)-induced colitis in mice, thereby demonstrating its potential therapeutic use in inflammatory bowel diseases (174). Taking advantage of these adaptive mechanisms of the schistosome parasite thus offers promise in the management of various autoimmune and inflammatory conditions. More immunomodulatory molecules and their interactomes and mechanisms need to be identified and characterized to develop effective drugs to achieve this end.

\section{AUTHOR CONTRIBUTIONS}

JA, VM, and PR contributed on the conception of the review paper. JA wrote the first draft of the manuscript. JA, VM, and PR wrote sections of the manuscript. All authors contributed to manuscript revision, read, and approved the submitted version.

\section{ACKNOWLEDGMENTS}

The authors are grateful to Dr. Furukawa Yu of Nikkei Business Publications, Inc. for providing the illustrations of the schistosome parasite used in Figure 1. 


\section{REFERENCES}

1. Allen JE, Maizels RM. Diversity and dialogue in immunity to helminthes. Nat Rev Immunol. (2011) 11:375-88. doi: 10.1038/nri2992

2. Zakeri A, Hansen EP, Andersen SD, Williams AR, Nejsum P. Immunomodulation by helminths: intracellular pathways and extracellular vesicles. Front Immunol. (2018) 9:2349. doi: 10.3389/fimmu.2018.02349

3. Maizels RM. Parasite immunomodulation and polymorphisms of the immune system. J Biol. (2009) 8:62. doi: 10.1186/jbiol166

4. Wilson MS, Mentink-Kane MM, Pesce JT, Ramalingam TR, Thompson R, Wynn TA. Immunopathology of schistosomiasis. Immunol Cell Biol. (2007) 85:148-54. doi: 10.1038/sj.icb.7100014

5. Wheater PR, Wilson RA. Schistosoma mansoni: a histological study of migration in the laboratory mouse. Parasitology. (1979) 79:4962. doi: 10.1017/S0031182000051970

6. Incani RN, McLaren DJ. Histopathological and ultrastructural studies of cutaneous reactions elicited in naive and chronically infected mice by invading schistosomula of Schistosoma mansoni. Int J Parasitol. (1984) 14:259-76. doi: 10.1016/0020-7519(84)90077-8

7. Hogg KG, Kumkate S, Anderson S, Mountford AP. Interleukin-12 p40 secretion by cutaneous $\mathrm{CD}_{11 \mathrm{c}^{+}}$and $\mathrm{F} 4 / 80^{+}$cells is a major feature of the innate immune response in mice that develop Th1-mediated protective immunity to Schistosoma mansoni. Infect Immun. (2003) 71:356371. doi: 10.1128/IAI.71.6.3563-3571.2003

8. Hogg KG, Kumkate S, Mountford AP. IL-10 regulates early IL-12-mediated immune responses induced by the radiation-attenuated schistosome vaccine. Int Immunol. (2003) 15:1451-9. doi: 10.1093/intimm/dxg142

9. Hesse M, Piccirillo CA, Belkaid Y, Prufer J, Mentink-Kane M, Leusink $\mathrm{M}$, et al. The pathogenesis of schistosomiasis is controlled by cooperating IL-10-producing innate effector and regulatory T cells. J Immunol. (2004) 172:3157-66. doi: 10.4049/jimmunol.172.5.3157

10. Sanin DE, Mountford AP. Sm16, a major component of Schistosoma mansoni cercarial excretory/secretory products, prevents macrophage classical activation and delays antigen processing. Parasit Vectors. (2015) 8:0608. doi: 10.1186/s13071-014-0608-1

11. Brännström K, Sellin ME, Holmfeldt P, Brattsand M, Gullberg M. The Schistosoma mansoni protein Sm16/SmSLP/SmSPO-1 assembles into a ninesubunit oligomer with potential to inhibit toll-like receptor signaling. Infect Immun. (2009) 77:1144-54. doi: 10.1128/IAI.01126-08

12. Liu T, Zhang L, Joo D, Sun SC. NF-кB signaling in inflammation. Signal Transduct Target Ther. (2017) 2:17023. doi: 10.1038/sigtrans.2017.23

13. Ramaswamy K, Kumar P, He YX. A role for parasite-induced PGE2 in IL-10mediated host immunoregulation by skin stage schistosomula of Schistosoma mansoni. J Immunol. (2000) 165:4567-74. doi: 10.4049/jimmunol.165.8.4567

14. Harizi H, Juzan M, Pitard V, Moreau JF, Gualde N. Cyclooxygenase-2issued prostaglandin $\mathrm{E}_{2}$ enhances the production of endogenous IL-10, which down-regulates dendritic cell functions. J Immunol. (2002) 168:225563. doi: 10.4049/jimmunol.168.5.2255

15. Ruzicka T, Printz MP. Arachidonic acid metabolism in skin: a review. Rev Physiol Biochem Pharmacol. (1984) 100:122. doi: 10.1007/3540133275_3

16. Matejuk A. Skin immunity. Arch Immunol Ther Exp. (2018) 66:4554. doi: 10.1007/s00005-017-0477-3

17. Kaplan DH, Kissenpfennig A, Clausen BE. Insights into Langerhans cell function from Langerhans cell ablation models. Eur J Immunol. (2008) 38:2369-76. doi: 10.1002/eji.200838397

18. Shklovskaya E, O’Sullivan BJ, Ng LG, Roediger B, Thomas R, Weninger W, et al. Langerhans cells are precommitted to immune tolerance induction. Proc Natl Acad Sci USA. (2011) 108:18049-54. doi: 10.1073/pnas.1110076108

19. Yoshiki R, Kabashima K, Sugita K, Atarashi K, Shimauchi T, Tokura Y. IL10-producing Langerhans cells and regulatory $\mathrm{T}$ cells are responsible for depressed contact hypersensitivity in grafted skin. J Invest Dermatol. (2009) 129:705-13. doi: 10.1038/jid.2008.304

20. Winzler C, Rovere P, Rescigno M, Granucci F, Penna G, Adorini L, et al. Maturation stages of mouse dendritic cells in growth factor-dependent long-term culture. J Exp Med. (1997) 185:317-28. doi: 10.1084/jem.185.2.317

21. Angeli V, Faveeuw C, Roye O, Fontaine J, Teissier E, Capron A, et al. Role of the parasite-derived prostaglandin D2 in the inhibition of epidermal
Langerhans cell migration during schistosomiasis infection. J Exp Med. (2001) 193:1135-47. doi: 10.1084/jem.193.10.1135

22. Catto BA, Lewis FA, Ottesen EA. Cercaria-induced histamine release: a factor in the pathogenesis of schistosome dermatitis? Am J Trop Med Hyg. (1980) 29:886-9. doi: 10.4269/ajtmh.1980.29.886

23. Rao KV, Chen L, Gnanasekar M, Ramaswamy K. Cloning and characterization of a calcium-binding, histamine-releasing protein from Schistosoma mansoni. J Biol Chem. (2002) 277:3120713. doi: 10.1074/jbc.M204114200

24. Mazzoni A, Young HA, Spitzer JH, Visintin A, Segal DM. Histamine regulates cytokine production in maturing dendritic cells, resulting in altered $\mathrm{T}$ cell polarization. J Clin Invest. (2001) 108:1865-73. doi: 10.1172/JCI200113930

25. Jutel $M$, Watanabe $\mathrm{T}$, Akdis $\mathrm{M}$, Blaser $\mathrm{K}$, Akdis CA. Immune regulation by histamine. Curr Opin Immunol. (2002) 14:73540. doi: 10.1016/S0952-7915(02)00395-3

26. van der Pouw Kraan TC, Snijders A, Boeije LC, de Groot ER, Alewijnse $\mathrm{AE}$, Leurs R, et al. Histamine inhibits the production of interleukin-12 through interaction with H2 receptors. J Clin Invest. (1998) 102:186673. doi: $10.1172 /$ JCI3692

27. James ER, Green DR. Manipulation of apoptosis in the host-parasite interaction. Trends Parasitol. (2004) 20:280-7. doi: 10.1016/j.pt.2004.04.004

28. Chen L, Rao KV, He YX, Ramaswamy K. Skin-stage schistosomula of Schistosoma mansoni produce an apoptosis-inducing factor that can cause apoptosis of T cells. J Biol Chem. (2002) 277:3432935. doi: 10.1074/jbc.M201344200

29. Jenkins SJ, Mountford AP. Dendritic cells activated with products released by schistosome larvae drive Th2-type immune responses, which can be inhibited by manipulation of CD40 co-stimulation. Infect Immun. (2005) 73:395-402. doi: 10.1128/IAI.73.1.395-402.2005

30. Pearce EJ, Kane CM, Sun J, Taylor JJ, McKee AS, Cervi L. Th2 response polarization during infection with the helminth parasite Schistosoma mansoni. Immunol Rev. (2004) 201:11726. doi: 10.1111/j.0105-2896.2004.00187.x

31. de Oliveira Fraga LA, Torrero MN, Tocheva AS, Mitre E, Davies SJ. Induction of type 2 responses by schistosome worms during prepatent infection. J Infect Dis. (2010) 201:464-72. doi: 10.1086/649841

32. El-Ridi R, Mohamed SH, Tallima H. Incubation of Schistosoma mansoni lung-stage schistosomula in corn oil exposes their surface membrane antigenic specificities. J Parasitol. (2003) 89:1064-7. doi: 10.1645/GE-3122RN

33. Lawson BWL, Bickle QD, Taylor MG. Mechanisms involved in the loss of antibody-mediated adherence of macrophages to lung-stage schistosomula of Schistosoma mansoni in vitro. Parasitology. (1993) 106:46369. doi: 10.1017/S0031182000076757

34. Parizade M, Arnon R, Lachmann PJ, Fishelson Z. Functional and antigenic similarities between a $94-\mathrm{kD}$ protein of Schistosoma mansoni (SCIP-1) and human CD59. J Exp Med. (1994) 179:1625-36. doi: 10.1084/jem.179.5.1625

35. Gobert GN, Stenzel DJ, McManus DP, Jones MK. The ultrastructural architecture of the adult Schistosoma japonicum tegument. Int J Parasitol. (2003) 33:1561-75. doi: 10.1016/S0020-7519(03)00255-8

36. Capron M, Capron A. Rats, mice and men - models for immune effector mechanisms against schistosomiasis. Parasitol Today. (1986) 2:6975. doi: 10.1016/0169-4758(86)90158-4

37. Skelly PJ. Intravascular schistosomes and complement. Trends Parasitol. (2004) 20:370-4. doi: 10.1016/j.pt.2004.05.007

38. Skelly PJ, Wilson RA. Making sense of the schistosome surface. Adv Parasitol. (2006) 63:185-284. doi: 10.1016/S0065-308X(06)63003-0

39. Roh JS, Sohn DH. Damage-associated molecular patterns in inflammatory diseases. Immune Net. (2018) 18:e27. doi: 10.4110/in.2018.18.e27

40. Bours MJ, Swennen EL, Di Virgilio F, Cronstein BN, Dagnelie PC. Adenosine $5^{\prime}$-triphosphate and adenosine as endogenous signaling molecules in immunity and inflammation. Pharmacol Ther. (2006) 112:358-404. doi: 10.1016/j.pharmthera.2005.04.013

41. Bhardwaj R, Skelly PJ. Characterization of schistosome tegumental alkaline phosphatase (SmAP). PLOS Negl Trop Dis. (2011) 5:e1011. doi: 10.1371/journal.pntd.0001011 
42. Bhardwaj R, Krautz-Peterson G, Da'dara A, Tzipori S, Skelly PJ. Tegumental phosphodiesterase SmNPP-5 is a virulence factor for schistosomes. Infect Immun. (2011) 79:4276-84. doi: 10.1128/IAI.05431-11

43. DeMarco R, Kowaltowski AT, Mortara RA, Verjovski-Almeida S. Molecular characterization and immunolocalization of Schistosoma mansoni ATP-diphosphohydrolase. Biochem Biophys Res Commun. (2003) 307:831-8. doi: 10.1016/S0006-291X(03) 01268-3

44. Bhardwaj R, Skelly PJ. Purinergic signaling and immune modulation at the schistosome surface? Trends Parasitol. (2009) 25:256-60. doi: 10.1016/j.pt.2009.03.004

45. Da'dara AA, Skelly PJ. Schistosomes versus platelets. Thromb Res. (2014) 134:1176-81. doi: 10.1016/j.thromres.2014.09.032

46. Joseph M, Auriault C, Capron A, Vorng H, Viens P. A new function for platelets: IgE-dependent killing of schistosomes. Nature. (1983) 303:8102. doi: $10.1038 / 303810 \mathrm{a} 0$

47. Da'dara AA, Bhardwaj R, Ali YB, Skelly PJ. Schistosome tegumental ectoapyrase (SmATPDase1) degrades exogenous pro-inflammatory and prothrombotic nucleotides. PeerJ. (2014) 2:e316. doi: 10.7717/peerj.316

48. Elzoheiry M, Da'dara AA, Nation CS, El-Beshbishi SN, Skelly PJ. Schistosomes can hydrolyze pro-inflammatory and pro-thrombotic polyphosphate (polyP) via tegumental alkaline phosphatase, SmAP. Mol Biochem Parasitol. (2019) 232:111190. doi: 10.1016/j.molbiopara.2019.111190

49. Elzoheiry M, Da'dara AA, deLaforcade AM, El-Beshbishi SN, Skelly PJ. The essential ectoenzyme SmNPP5 from the human intravascular parasite Schistosoma mansoni is an ADPase and a potent inhibitor of platelet aggregation. Thromb Haemost. (2018) 118:979-89. doi: 10.1055/s-0038-1641715

50. Ruiz FA, Lea CR, Oldfield E, Docampo R. Human platelet dense granules contain polyphosphate and are similar to acidocalcisomes of bacteria and unicellular eukaryotes. J Biol Chem. (2004) 279:442507. doi: 10.1074/jbc.M406261200

51. Moreno-Sanchez D, Hernandez-Ruiz L, Ruiz F, Docampo R. Polyphosphate is a novel pro-inflammatory regulator of mast cells and is located in acidocalcisomes. J Biol Chem. (2012) 287:28435-44. doi: 10.1074/jbc.M112.385823

52. Muller F, Mutch NJ, Schenk WA, Smith SA, Esterl L, Spronk HM, et al. Platelet polyphosphates are proinflammatory and procoagulant mediators in vivo. Cell. (2009) 139:1143-56. doi: 10.1016/j.cell.2009. 11.001

53. Santoro F, Lachmann PJ, Capron A, Capron M. Activation of complement by Schistosoma mansoni schistosomula: killing of parasites by the alternative pathway and requirement of IgG for classical pathway activation. J Immunol. (1979) 123:1551-7.

54. Omer-Ali P, Magee AI, Kelly C, Simpson AJ. A major role for carbohydrate epitopes preferentially recognized by chronically infected mice in the determination of Schistosoma mansoni schistosomulum surface antigenicity. J Immunol. (1986) 137:3601-7.

55. Racoosin EL, Davies SJ, Pearce EJ. Caveolae-like structures in the surface membrane of Schistosoma mansoni. Mol Biochem Parasitol. (1999) 104:28597. doi: 10.1016/S0166-6851(99)00156-5

56. Brown DA. Lipid rafts, detergent-resistant membranes, and raft targeting signals. Physiology. (2006) 21:430-9. doi: 10.1152/physiol.00032.2006

57. Lingwood D, Simons K. Lipid rafts as a membrane-organizing principle. Science. (2010) 327:46-50. doi: 10.1126/science.1174621

58. Ressurreição M, Elbeyioglu F, Kirk RS, Rollinson D, Emery AM, Page $\mathrm{NM}$, et al. Molecular characterization of host-parasite cell signalling in Schistosoma mansoni during early development. Sci Rep. (2016) 6:35614. doi: 10.1038/srep35614

59. Krishna M, Narang H. The complexity of mitogen-activated protein kinases (MAPKs) made simple. Cell Mol Life Sci. (2008) 65:352544. doi: 10.1007/s00018-008-8170-7

60. Newton AC. Protein kinase C: poised to signal. Am J Physiol Endocrinol Metab. (2010) 298:E395-E402. doi: 10.1152/ajpendo.00477.2009

61. Chai M, McManus DP, McInnes R, Moertel LP, Tran M, Loukas A, et al. Transcriptome profiling of lung schistosomula, in vitro cultured schistosomula and the adult Schistosoma japonicum. Cell Mol Life Sci. (2006) 63:919-29. doi: 10.1007/s00018-005-5578-1

62. Loukas A, Jones MK, King LT, Brindley PJ, McManus DP. Receptor for Fc on the surface of schistosomes. Infect Immun. (2001) 69:364651. doi: 10.1128/IAI.69.6.3646-3651.2001

63. Laclette JP, Shoemaker CB, Richter D, Arcos L, Pante N, Cohen C, et al Paramyosin inhibits complement C1. J Immunol. (1992) 148:124-8.

64. Muro A, Pérez-Arellano JL. Nitric oxide and respiratory helminthic diseases. J Biomed Biotechnol. (2010) 2010:958108. doi: 10.1155/2010/958108

65. García-Ortiz A, Serrador JM. Nitric oxide signaling in $T$ cell-mediated immunity. Trends Mol Med. (2018) 24:41227. doi: 10.1016/j.molmed.2018.02.002

66. Coulson PS, Smythies LE, Betts C, Mabbott NA, Sternberg JM, Wei $\mathrm{XG}$, et al. Nitric oxide produced in the lungs of mice immunized with the radiation-attenuated schistosome vaccine is not the major agent causing challenge parasite elimination. Immunol. (1998) 93:5563. doi: 10.1046/j.1365-2567.1998.00405.x

67. Ahmed SF, Oswald IP, Caspar P, Hieny S, Keefer L, Sher A, et al. Developmental differences determine larval susceptibility to nitric oxide-mediated killing in a murine model of vaccination against Schistosoma mansoni. Infect Immun. (1997) 65:21926. doi: 10.1128/IAI.65.1.219-226.1997

68. Horemans AM, Tielens AG, van den Bergh SG. The reversible effect of glucose on the energy metabolism of Schistosoma mansoni cercariae and schistosomula. Mol Biochem Parasitol. (1992) 51:73-9. doi: 10.1016/0166-6851(92)90202-U

69. Tielens AG. Energy generation in parasitic helminths. Parasitol Today. (1994) 10:346-52. doi: 10.1016/0169-4758(94)90245-3

70. Skelly PJ, Stein LD, Shoemaker CB. Expression of Schistosoma mansoni genes involved in anaerobic and oxidative glucose metabolism during the cercaria to adult transformation. Mol Biochem Parasitol. (1993) 60:93104. doi: 10.1016/0166-6851(93)90032-S

71. Skelly PJ. Shoemaker CB. A molecular genetic study of the variations in metabolic function during schistosome development. Mem Inst Oswaldo Cruz. (1995) 90:281-4. doi: 10.1590/S0074-02761995000200027

72. Conrad ME. Hematologic manifestations of parasitic infections. Semin Hematol. (1971) 8:267-303.

73. Goldring OL, Clegg JA, Smithers SR, Terry RJ. Acquisition of human blood group antigens by Schistosoma mansoni. Clin Exp Immunol. (1976) 26:181-7.

74. Sher A, Hall BF, Vadas A. Acquisition of murine major histocompatibility complex gene products by schistosomula of Schistosoma mansoni. J Exp Med. (1978) 148:46-57. doi: 10.1084/jem.148.1.46

75. Tarleton RL, Kemp WM. Demonstration of IgG-Fc and C3 receptors on adult Schistosoma mansoni. J Immunol. (1981) 126:379-84.

76. Sun X, Funk CD, Deng C, Sahu A, Lambris JD, Song WC. Role of decayaccelerating factor in regulating complement activation on the erythrocyte surface as revealed by gene targeting. Proc Natl Acad Sci USA. (1999) 96:628-33. doi: 10.1073/pnas.96.2.628

77. Horta MF, Ramalho-Pinto FJ. Role of human decay-accelerating factor in the evasion of Schistosoma mansoni from the complement-mediated killing in vitro. Exp Med. (1991) 174:1399-406. doi: 10.1084/jem.174.6.1399

78. Inal JM, Sim RB. A Schistosoma protein, Sh-TOR, is a novel inhibitor of complement which binds human C2. FEBS Lett. (2000) 470:1314. doi: 10.1016/S0014-5793(00)01304-1

79. Deng J, Gold D, LoVerde PT, Fishelson Z. Inhibition of the complement membrane attack complex by Schistosoma mansoni paramyosin. Infect Immun. (2003) 71:6402-10. doi: 10.1128/IAI.71.11.6402-6410.2003

80. Silveira-Lemos D, Fernandes Costa-Silva M, Cardoso de Oliveira Silveira A, Azevedo Batista M, Alves Oliveira-Fraga L, Soares Silveira AM, et al. Cytokine pattern of $\mathrm{T}$ lymphocytes in acute schistosomiasis mansoni patients following treated praziquantel therapy. J Parasitol Res. (2013) 2013:909134. doi: 10.1155/2013/909134

81. Kawasaki T, Kawai T. Toll-like receptor signaling pathways. Front Immunol. (2014) 5:461. doi: 10.3389/fimmu.2014.00461

82. Dabbagh K, Lewis DB. Toll-like receptors and T-helper-1/Thelper-2 responses. Curr Opin Infect Dis. (2003) 16:199204. doi: 10.1097/00001432-200306000-00003 
83. Robinson DS, O'Garra A. Further checkpoints in Th1 development. Immun. (2002) 16:755-8. doi: 10.1016/S1074-7613(02)00331-X

84. van der Kleij D, Latz E, Brouwers JF, Kruize YC, Schmitz M, KurtJones EA, et al. A novel host-parasite lipid cross-talk. Schistosomal lyso-phosphatidylserine activates toll-like receptor 2 and affects immune polarization. J Biol Chem. (2002) 277:48122-9. doi: 10.1074/jbc.M206941200

85. Thomas PG, Carter MR, Atochina O, Da’Dara AA, Piskorska D, McGuire E, et al. Maturation of dendritic cell 2 phenotype by a helminth glycan uses a toll-like receptor 4-dependent mechanism. J Immunol. (2003) 171:583741. doi: 10.4049/jimmunol.171.11.5837

86. Agrawal S, Agrawal A, Doughty B, Gerwitz A, Blenis J, Van Dyke T, et al. Cutting edge: different toll-like receptor agonists instruct dendritic cells to induce distinct Th responses via differential modulation of extracellular signal-regulated kinase mitogen-activated protein kinase and c-Fos. $J$ Immunol. (2003) 171:4984-9. doi: 10.4049/jimmunol.171.10.4984

87. Odegaard JI, Hsieh MH. Immune responses to Schistosoma haematobium infection. Parasite Immunol. (2014) 36:428-38. doi: 10.1111/pim.12084

88. Fu C-L, Odegaard JI, Herbert DR, Hsieh MH. A novel mouse model of Schistosoma haematobium egg-induced immunopathology. PLoS Pathog. (2012) 8:e1002605. doi: 10.1371/journal.ppat.1002605

89. Pearce EJ. Priming of the immune response by schistosome eggs. Parasit Immunol. (2005) 27:265-70. doi: 10.1111/j.1365-3024.2005.00765.x

90. Pearce EJ, Macdonald AS. The immunobiology of schistosomiasis. Nat Rev Immunol. (2002) 2:499-511. doi: 10.1038/nri843

91. Schwartz C, Oeser K, Prazeres Da Costa C, Layland LE, Voehringer D. T cell derived IL-4/IL-13 protects mice against fatal Schistosoma mansoni infection independently of basophils. J Immunol. (2014) 193:35909. doi: 10.4049/jimmunol.1401155

92. Schramm G, Falcone FH, Gronow A, Haisch K, Mamat U, Doenhoff MJ, et al. Molecular characterization of an interleukin-4inducing factor from Schistosoma mansoni eggs. J Biol Chem. (2003) 278:18384-92. doi: 10.1074/jbc.M300497200

93. Steinfelder S, Andersen JF, Cannons JL, Feng CG, Joshi M, Dwyer D, et al. The major component in schistosome eggs responsible for conditioning dendritic cells for Th2 polarization is a T2 ribonuclease (omega-1). J Exp Med. (2009) 206:1681-90. doi: 10.1084/jem.20082462

94. Everts B, Perona-Wright G, Smits HH, Hokke CH, van der Ham AJ, Fitzsimmons CM, et al. Omega-1, a glycoprotein secreted by Schistosoma mansoni eggs, drives Th2 responses. J Exp Med. (2009) 206:167380. doi: $10.1084 /$ jem. 20082460

95. Everts B, Hussaarts L, Driessen NN, Meevissen MH, Schramm G, van der Ham AJ, et al. Schistosome-derived omega-1 drives Th2 polarization by suppressing protein synthesis following internalization by the mannose receptor. J Exp Med. (2012) 209:1753-67. doi: 10.1084/jem.20111381

96. Wu GY, Halim MH. Schistosomiasis: progress and problems. World J Gastroenterol. (2000) 6:12-9. doi: 10.3748/wjg.v6.i1.12

97. Costain AH, MacDonald AS, Smits HH. Schistosome egg migration: mechanisms, pathogenesis and host immune responses. Front Immunol. (2018) 9:3042. doi: 10.3389/fimmu.2018.03042

98. Doenhoff MJ, Pearson S, Dunne DW, Bickle Q, Lucas S, Bain J, et al. Immunological control of hepatotoxicity and parasite egg excretion in Schistosoma mansoni infections: stage specificity of the reactivity of immune serum in T-cell deprived mice. Trans R Soc Trop Med Hyg. (1981) 75:4153. doi: 10.1016/0035-9203(81)90012-2

99. Phillips SM, Diconza JJ, Gold JA, Reid WA. Schistosomiasis in the congenitally athymic (nude) mouse. I Thymic dependency of eosinophilia, granuloma formation, and host morbidity. J Immunol. (1977) 118:594-9.

100. Mathew RC, Boros DL. Anti-L3T4 antibody treatment suppresses hepatic granuloma formation and abrogates antigen-induced interleukin-2 production in Schistosoma mansoni infection. Infect Immun. (1986) 54:820-6. doi: 10.1128/IAI.54.3.820-826.1986

101. Byram JE, Von Lichtenberg F. Altered schistosome granuloma formation in nude mice. Am J Trop Med Hyg. (1977) 26:94456. doi: 10.4269/ajtmh.1977.26.944

102. Mathieson W, Wilson RA. A comparative proteomic study of the undeveloped and developed Schistosoma mansoni egg and its contents: the miracidium, hatch fluid and secretions. Int J Parasitol. (2010) 40:61728, doi: 10.1016/j.ijpara.2009.10.014
103. Figueiredo BC, Da'dara AA, Oliveira SC, Skelly PJ. Schistosomes enhance plasminogen activation: the role of tegumental enolase. PLoS Pathog. (2015) 11:e1005335. doi: 10.1371/journal.ppat.1005335

104. Pirovich DB, Da'dara AA, Skelly PJ. Schistosoma mansoni glyceraldehyde3-phosphate dehydrogenase enhances formation of the blood-clot lysis protein plasmin. Biol Open. (2020) 9:bio.050385. doi: 10.1242/bio. 050385

105. Schwartz C, Fallon PG. Schistosoma "eggs-iting" the host: granuloma formation and egg excretion. Front Immunol. (2018) 9:2492. doi: 10.3389/fimmu.2018.02492

106. Doenhoff M, Musallam R, Bain J, Mcgregor A. Studies on the host-parasite relationship in Schistosoma mansoni-infected mice: the immunological dependence of parasite egg excretion. Immunology. (1978) 35:771-8.

107. Brunet LR, Finkelman FD, Cheever AW, Kopf MA, Pearce EJ. IL-4 protects against TNF- $\alpha$-mediated cachexia and death during acute schistosomiasis. $J$ Immunol. (1997) 159:777-85.

108. Fallon PG, Richardson EJ, Mckenzie GJ, Mckenzie AN. Schistosome infection of transgenic mice defines distinct and contrasting pathogenic roles for IL-4 and IL-13: IL-13 is a profibrotic agent. J Immunol. (2000) 164:258591. doi: 10.4049/jimmunol.164.5.2585

109. Kaplan MH, Whitfield JR, Boros DL, Grusby MJ. Th2 cells are required for the Schistosoma mansoni egg-induced granulomatous response. J Immunol. (1998) 160:1850-6.

110. Jankovic D, Kullberg MC, Noben-Trauth N, Caspar P, Ward JM, Cheever AW, et al. Schistosome-infected IL-4 receptor knockout (KO) mice, in contrast to IL-4 KO mice, fail to develop granulomatous pathology while maintaining the same lymphokine expression profile. J Immunol. (1999) 163:337-42.

111. Stadecker MJ, Asahi H, Finger E, Hernandez HJ, Rutitzky LI, Sun J. The immunobiology of Th1 polarization in high-pathology schistosomiasis. Immunol Rev. (2004) 201:168-79. doi: 10.1111/j.0105-2896.2004.00197.x

112. Reiman RM, Thompson RW, Feng CG, Hari D, Knight R, Cheever AW, et al. Interleukin-5 (IL-5) augments the progression of liver fibrosis by regulating IL-13 activity. Infect Immun. (2006) 74:14719. doi: 10.1128/IAI.74.3.1471-1479.2006

113. Hoffmann KF, Cheever AW, Wynn TA. IL-10 and the dangers of immune polarization: excessive type 1 and type 2 cytokine responses induce distinct forms of lethal immunopathology in murine schistosomiasis. J Immunol. (2000) 164:6406-16. doi: 10.4049/jimmunol.164.12.6406

114. Mwatha JK, Kimani G, Kamau T, Mbugua GG, Ouma JH, Mumo J, et al. High levels of TNF, soluble TNF receptors, soluble ICAM-1, and IFN-gamma, but low levels of IL-5, are associated with hepatosplenic disease in human schistosomiasis mansoni. J Immunol. (1998) 160:1992-9.

115. Smith P, Fallon RE, Mangan NE, Walsh CM, Saraiva M, Sayers JR, et al. Schistosoma mansoni secretes a chemokine binding protein with anti-inflammatory activity. J Exp Med. (2005) 202:1319-25. doi: 10.1084/jem.20050955

116. Boros DL, Whitfield JR. Enhanced Th1 and dampened Th2 responses synergize to inhibit acute granulomatous and fibrotic responses in murine schistosomiasis mansoni. Infect Immun. (1999) 67:1187-93. doi: 10.1128/IAI.67.3.1187-1193.1999

117. Chuah C, Jones MK, Burke ML, Owen HC, Anthony BJ, McManus DP, et al. Spatial and temporal transcriptomics of Schistosoma japonicum-induced hepatic granuloma formation reveals novel roles for neutrophils. J Leukoc Biol. (2013) 94:353-65. doi: 10.1189/jlb.1212653

118. Wu C, Chen Q, Fang Y, Wu J, Han Y, Wang Y, et al. Schistosoma japonicum egg specific protein SjE16.7 recruits neutrophils and induces inflammatory hepatic granuloma initiation. PLoS Negl Trop Dis. (2014) 8:e2703. doi: 10.1371/journal.pntd.0002703

119. Chuah C, Jones MK, Burke ML, McManus DP, Owen HC, Gobert GN. Defining a pro-inflammatory neutrophil phenotype in response to schistosome eggs. Cell Microbiol. (2014) 16:1666-77. doi: 10.1111/cmi.12316

120. Baker VS, Imade GE, Molta NB, Tawde P, Pam SD, Obadofin MO, et al. Cytokine-associated neutrophil extracellular traps and antinuclear antibodies in Plasmodium falciparum infected children under six years of age. Malar J. (2008) 7:41. doi: 10.1186/1475-2875-7-41

121. Bonne-Année S, Kerepesi LA, Hess JA, Wesolowski J, Paumet F, Lok JB, et al. Extracellular traps are associated with human and mouse neutrophil 
and macrophage mediated killing of larval Strongyloides stercoralis. Microbes Infect. (2014) 16:502-11. doi: 10.1016/j.micinf.2014.02.012

122. Hirata, M. Hara T, Kage M, Fukuma T, Sendo F. Neutropenia augments experimentally induced Schistosoma japonicum egg granuloma formation in CBA mice, but not in C57BL/6 mice. Parasite Immunol. (2002) 24:47988. doi: 10.1046/j.1365-3024.2002.00491.x

123. Hirata M, Fukuma T. Cytokine regulation in experimentally-induced Schistosoma japonicum egg granuloma formation. Parasitol Int. (2003) 52:341-9. doi: 10.1016/S1383-5769(03)00050-3

124. Burke ML, McManus DP, Ramm GA, Duke M, Li Y, Jones MK, et al. Temporal expression of chemokines dictates the hepatic inflammatory infiltrate in a murine model of schistosomiasis. PLoS Negl Trop Dis. (2010) 4:e598. doi: 10.1371/journal.pntd.0000598

125. Moore DL, Grove DI, Warren KS. The Schistosoma mansoni egg granuloma: quantitation of cell populations. J Pathol. (1977) 121:4150. doi: $10.1002 /$ path. 1711210107

126. Fallon PG, Smith P, Dunne DW. Type 1 and type 2 cytokineproducing mouse CD4+ and CD8+ T cells in acute Schistosoma mansoni infection. Eur J Immunol. (1998) 28:1408-16. doi: 10.1002/(SICI)15214141(199804)28:04<1408::AID-IMMU1408>3.0.CO;2-H

127. Jankovic D, Cheever AW, Kullberg MC, Wynn TA, Yap G, Caspar P, et al. CD4+ T cell-mediated granulomatous pathology in schistosomiasis is downregulated by a B cell-dependent mechanism requiring Fc receptor signaling. J Exp Med. (1998) 187:619-29. doi: 10.1084/jem.187.4.619

128. Herbert DR, Hölscher C, Mohrs M, Arendse B, Schwegmann A, Radwanska $M$, et al. Alternative macrophage activation is essential for survival during schistosomiasis and downmodulates $\mathrm{T}$ helper 1 responses and immunopathology. Immunity. (2004) 20:623-35. doi: 10.1016/S1074-7613(04)00107-4

129. Sher A, Coffman RL, Hieny S, Scott P, Cheever AW. Interleukin 5 is required for the blood and tissue eosinophilia but not granuloma formation induced by infection with Schistosoma mansoni. Proc Natl Acad Sci USA. (1990) 87:61-5. doi: 10.1073/pnas.87.1.61

130. Chiaramonte MG, Donaldson DD, Cheever AW, Wynn TA. An IL-13 inhibitor blocks the development of hepatic fibrosis during a T-helper type 2-dominated inflammatory response. J Clin Invest. (1999) 104:77785. doi: $10.1172 /$ JCI7325

131. Hsu SY, Hsu HF, Mitros FA, Helms CM, Solomon RI. Eosinophils as effector cells in the destruction of Schistosoma mansoni eggs in granulomas. Ann Trop Med Parasitol. (1980) 74:179-83. doi: 10.1080/00034983.1980.11687328

132. Rumbley CA, Sugaya H, Zekavat SA, El Refaei M, Perrin PJ, Phillips SM. Activated eosinophils are the major source of Th2-associated cytokines in the schistosome granuloma. J Immunol. (1999) 162:1003-9.

133. Von Lichtenberg F, Erickson DG, Sadun EH. Comparative histopathology of schistosome granulomas in the hamster. Am J Pathol. (1973) 72:149-78.

134. Amaral KB, Silva TP, Dias FF, Malta KK, Rosa FM, Costa-Neto SF, et al. Histological assessment of granulomas in natural and experimental Schistosoma mansoni infections using whole slide imaging. PLoS ONE. (2017) 12:e0184696. doi: 10.1371/journal.pone.0184696

135. Punnonen J, Carballido JM, Aversa G, de Vries JE. Interleukin 13 and its receptor. In: Delves PJ, Roitt IM, editors. Encyclopedia of Immunology (Second Edition). San Diego, CA: Publisher is Academic Press (1998). p. 1489-92.

136. Liu Y, Munker S, Müllenbach R, Weng HL. IL-13 signaling in liver fibrogenesis. Front Immunol. (2012) 3:116. doi: 10.3389/fimmu.2012.00116

137. Hesse M, Modolell M, La Flamme AC, Schito M, Fuentes JM, Cheever AW, et al. Differential regulation of nitric oxide synthase- 2 and arginase1 by type 1/type 2 cytokines in vivo: granulomatous pathology is shaped by the pattern of 1 -arginine metabolism. I Immunol. (2001) 167:653344. doi: 10.4049/jimmunol.167.11.6533

138. Anthony BJ, Ramm GA, McManus DP. Role of resident liver cells in the pathogenesis of schistosomiasis. Trends Parasitol. (2012) 28:5729. doi: 10.1016/j.pt.2012.09.005

139. Dunne DW, Jones FM, Doenhoff MJ. The purification, characterization, serological activity and hepatotoxic properties of two cationic glycoproteins (alpha 1 and omega 1) from Schistosoma mansoni eggs. Parasitology. (1991) 103(Pt2):225-36. doi: 10.1017/S0031182000059503
140. Tesmer LA, Lundy SK, Sarkar S, Fox DA. Th17 cells in human disease. Immunol Rev. (2008) 223:87-113. doi: 10.1111/j.1600-065X.2008.00628.x

141. Wen X, He L, Chi Y, Zhou S, Hoellwarth J, Zhang C, et al. Dynamics of Th17 cells and their role in Schistosoma japonicum infection in C57BL/6 mice. PLoS Negl Trop Dis. (2011) 5:e1399. doi: 10.1371/journal.pntd.0001399

142. Zhang Y, Chen L, Gao W, Hou X, Gu Y, Gui L, et al. IL-17 neutralization significantly ameliorates hepatic granulomatous inflammation and liver damage in Schistosoma japonicum infected mice. Eur J Immunol. (2012) 42:1523-35. doi: 10.1002/eji.201141933

143. Chen D, Luo X, Xie H, Gao Z, Fang H, Huang J. Characteristics of IL17 induction by Schistosoma japonicum infection in C57BL/6 mouse liver. Immunol. (2013) 139:523-32. doi: 10.1111/imm.12105

144. Rutitzky LI, Stadecker MJ. CD4 T cells producing pro-inflammatory interleukin-17 mediate high pathology in schistosomiasis. Mem Inst Oswaldo Cruz. (2006) 101:327-30. doi: 10.1590/S0074-02762006000900052

145. Shainheit MG, Lasocki KW, Finger E, Larkin BM, Smith PM, Sharpe AH, et al. The pathogenic Th17 cell response to major schistosome egg antigen is sequentially dependent on IL-23 and IL-1 $\beta$. J Immunol. (2011) 187:532835. doi: 10.4049/jimmunol.1101445

146. Bettelli E, Carrier Y, Gao W, Korn T, Strom TB, Oukka M, et al. Reciprocal developmental pathways for the generation of pathogenic effector TH17 and regulatory T cells. Nature. (2006) 441:235-8. doi: 10.1038/nature04753

147. Mangan PR, Harrington LE, O'Quinn DB, Helms WS, Bullard DC, Elson CO, et al. Transforming growth factor-beta induces development of the TH17 lineage. Nature. (2006) 441:231-4. doi: 10.1038/nature04754

148. Veldhoen M, Hocking RJ, Atkins CJ, Locksley RM, Stockinger B. TGFbeta in the context of an inflammatory cytokine milieu supports de novo differentiation of IL-17-producing T cells. Immunity. (2006) 24:17989. doi: 10.1016/j.immuni.2006.01.001

149. Li MO, Wan YY, Sanjabi S, Robertson A-KL, Flavell RA. Transforming growth factor-beta; regulation of immune responses. Annu Rev Immunol. (2006) 24:99-146. doi: 10.1146/annurev.immunol.24.021605. 090737

150. Martinez GJ, Nurieva RI, Yang XO, Dong C. Regulation and function of proinflammatory TH17 cells. Ann NY Acad Sci. (2008) 1143:188211. doi: 10.1196/annals.1443.021

151. Taylor A, Verhagen J, Blaser K, Akdis M, Akdis CA. Mechanisms of immune suppression by interleukin-10 and transforming growth factorbeta: the role of $\mathrm{T}$ regulatory cells. Immunology. (2006) 117:43342. doi: 10.1111/j.1365-2567.2006.02321.x

152. Xu L, Kitani A, Fuss I, Strober W. Cutting edge: regulatory $\mathrm{T}$ cells induce CD4+ CD25 - Foxp3-T cells or are self-induced to become Th17 cells in the absence of exogenous TGF- $\beta$. J Immunol. (2007) 178:67259. doi: 10.4049/jimmunol.178.11.6725

153. Annunziato F, Cosmi L, Santarlasci V, Maggi L, Liotta F, Mazzinghi B, et al. Phenotypic and functional features of human Th17 cells. J Exp Med. (2007) 204:1849-61. doi: $10.1084 /$ jem.20070663

154. Evans HG, Suddason T, Jackson I, Taams LS, Lord GM. Optimal induction of $\mathrm{T}$ helper 17 cells in humans requires $\mathrm{T}$ cell receptor ligation in the context of Toll-like receptor-activated monocytes. Proc Natl Acad Sci USA. (2007) 104:17034-9. doi: 10.1073/pnas.0708426104

155. Chen S, Gao Y, Liang Y, Hu L, Liu J, Peng L, et al. Imbalance of Th1/Th2 and Th17/Treg promoting schistosome egg granuloma formation. Int J Clin Exp Med. (2017) 10:14290-300.

156. Miller RL, Armelagos GJ, Ikram S, De Jonge N, Krijger FW, Deelder AM. Palaeoepidemiology of Schistosoma infection in mummies. BMJ. (1992) 304:555-6. doi: 10.1136/bmj.304.6826.555

157. Brown SP, Grenfell BT. An unlikely partnership: parasites, concomitant immunity and host defence. Proc Biol Sci. (2001) 268:2543-9. doi: 10.1098/rspb.2001.1821

158. Smithers SR, Terry RJ. Resistance to experimental infection with Schistosoma mansoni in rhesus monkeys induced by the transfer of adult worms. Trans Royal Soc Trop Med Hyg. (1967) 61:517-33. doi: 10.1016/0035-9203(67)90102-2

159. Coulson PS, Wilson RA. Affiliations expand examination of the mechanisms of pulmonary phase resistance to Schistosoma mansoni in vaccinated mice. Am J Trop Med Hyg. (1988) 38:529-39. doi: 10.4269/ajtmh.1988.38.529 
160. McSorley HJ, Hewitson JP, Maizels RM. Immunomodulation by helminth parasites: defining mechanisms and mediators. Int J Parasitol. (2013) 43:30110. doi: 10.1016/j.ijpara.2012.11.011

161. Strachan DP. Hay fever, hygiene, and household size. Brit Med J. (1989) 299:1259-60. doi: 10.1136/bmj.299.6710.1259

162. Osada Y, Shimizu S, Kumagai T, Yamada S, Kanazawa T. Schistosoma mansoni infection reduces severity of collagen-induced arthritis via downregulation of pro-inflammatory mediators. Int J Parasitol. (2009) 39:45764. doi: 10.1016/j.ijpara.2008.08.007

163. Song X, Shen J, Wen H, Zhong Z, Luo Q, Chu D, et al. Impact of Schistosoma japonicum infection on collagen-induced arthritis in DBA/1 mice: a murine model of human rheumatoid arthritis. PLoS ONE. (2011) 6:e23453. doi: 10.1371/journal.pone.00 23453

164. Osada Y, Yamada S, Nakae S, Sudo K, Kanazawa T. Reciprocal effects of Schistosoma mansoni infection on spontaneous autoimmune arthritis in IL-1 receptor antagonist-deficient mice. Parasitol Int. (2014) 64:137. doi: 10.1016/j.parint.2014.09.001

165. Maron R, Palanivel V, Weiner HL, Harn DA. Oral administration of schistosome egg antigens and insulin B-chain generates and enhances Th2type responses in NOD mice. Clin Immunol Immunopathol. (1998) 87:8592. doi: 10.1006/clin.1997.4506

166. Cooke A, Tonks P, Jones FM, O'Shea H, Hutchings P, Fulford AJ, et al. Infection with Schistosoma mansoni prevents insulin dependent diabetes mellitus in non-obese diabetic mice. Parasite Immunol. (1999) 21:16976. doi: 10.1046/j.1365-3024.1999.00213.x

167. Zaccone $\mathrm{P}$, Fehérvári Z, Jones FM, Sidobre S, Kronenberg M, Dunne DW, et al. Schistosoma mansoni antigens modulate the activity of the innate immune response and prevent onset of type 1 diabetes. Eur J Immunol. (2003) 33:1439-49. doi: 10.1002/eji.2003 23910

168. Zaccone P, Burton O, Miller N, Jones FM, Dunne DW, Cooke A. Schistosoma mansoni egg antigens induce Treg that participate in diabetes prevention in NOD mice. Eur J Immunol. (2009) 39:1098-107. doi: 10.1002/eji.2008 38871
169. Nagayama Y, Watanabe K, Niwa M, McLachlan SM, Rapoport B. Schistosoma mansoni and $\alpha$-galactosylceramide: prophylactic effect of Th1 immune suppression in a mouse model of Graves' hyperthyroidism. J Immunol. (2004) 173:2167-73. doi: 10.4049/jimmunol.173.3.2167

170. Mangan NE, van Rooijen N, McKenzie ANJ, Fallon PG. Helminthmodified pulmonary immune response protects mice from allergen-induced airway hyperresponsiveness. J Immunol. (2006) 176:138-47. doi: 10.4049/jimmunol.176.1.138

171. Mo HM, Lei JH, Jiang ZW, Wang CZ, Cheng YL, Li YL, et al. Schistosoma japonicum infection modulates the development of allergeninduced airway inflammation in mice. Parasitol Res. (2008) 103:11839. doi: 10.1007/s00436-008-1114-1

172. Bhargava P, Li C, Stanya KJ, Jacobi D, Dai L, Liu S, et al. Immunomodulatory glycan LNFPIII alleviates hepatosteatosis and insulin resistance through direct and indirect control of metabolic pathways. Nature Med. (2012) 18:1665-72. doi: 10.1038/nm.2962

173. Atochina O, Harn D. Prevention of psoriasis-like lesions development in fsn/fsn mice by helminth glycans. Exp Dermatol. (2006) 15:4618. doi: 10.1111/j.1600-0625.2006.00431.x

174. Wang S, Xie Y, Yang X, Wang X, Yan K, Zhong Z, et al. Therapeutic potential of recombinant cystatin from Schistosoma japonicum in TNBS-induced experimental colitis of mice. Parasit Vectors. (2016) 9:6. doi: 10.1186/s13071-015-1288-1

Conflict of Interest: The authors declare that the research was conducted in the absence of any commercial or financial relationships that could be construed as a potential conflict of interest.

Copyright () 2020 Angeles, Mercado and Rivera. This is an open-access article distributed under the terms of the Creative Commons Attribution License (CC BY). The use, distribution or reproduction in other forums is permitted, provided the original author(s) and the copyright owner(s) are credited and that the original publication in this journal is cited, in accordance with accepted academic practice. No use, distribution or reproduction is permitted which does not comply with these terms. 